\title{
A Conversation with Shanti Gupta
}

\author{
Gary C. McDonald
}

Abstract. Shanti Gupta was born and raised in Saunasi, Mainpuri, India. He attended Delhi University and received B.A. Honours and M.A. degrees in mathematics. He then took a one-year diploma course in applied statistics at the Indian Council of Agricultural Research, New Delhi, and his distinguished career in statistics was launched. He came to the United States in 1953 and received his Ph.D. in mathematical statistics in 1956 from the University of North Carolina at Chapel Hill working under the guidance of Professor Raj Chandra Bose. His thesis, "On a decision rule for a problem in ranking means," began his prolific formulation of and investigation into a class of problems referred to as "subset approach to ranking and selection."

Shanti has held research and teaching positions at Delhi College, Bell Telephone Laboratories, University of Alberta, Courant Institute of Mathematical Science at New York University, Stanford University and, most notably, Purdue University, where he has spent most of his professional career. At Purdue, he became Head of the newly created Department of Statistics in 1968 and served in that capacity until 1995 when he stepped down to devote more fully his time and energy to teaching and research. Under his leadership, Purdue's Department of Statistics grew into one of the premier departments in the country. Twenty-eight Ph.D. dissertations were directed by Shanti over this period of time.

Shanti has provided exemplary service to the profession. A partial list of his activities includes the following: Founding Editor of the IMS Lecture Notes-Monograph Series in Statistics and Probability (19791988); Chairman of the Joint Management Committee of the ASA and IMS for Current Index to Statistics (1981-1988); Member of the NRC Advisory Committee on U.S. Army Basic Scientific Research (19831988). He served as President of the IMS during 1989-1990. He has also been very active with many of the statistical journals, serving in both editorial and board-member capacities.

Shanti has received many honors in recognition of his valuable contributions. He is a Fellow of the ASA, AAAS and IMS and is an elected member of the International Statistical Institute. He has held special short-term visiting positions such as Special Chair, Institute of Mathematics, Academia Sinica, Taipei, Taiwan; and Erskine Fellow, University of Canterbury, Christchurch, New Zealand. He was one of the special invitees at the 1990 Taipei International Symposium in Statistics and was presented with the key to the city by the Mayor. A recent book, Advances in Statistical Decision Theory and Applications

Gary McDonald is Head, Operations Research Department, General Motors Global Research \& Development Operations, Warren, Michigan 48090-9055 (e-mail: Gary_McDonald@notes.gmr.com). 
(Birkhäuser, 1997), published in honor of Shanti, contains many papers in the areas where his influence as a teacher and a researcher have been felt: Bayesian inference; decision theory; point and interval estimation; tests of hypotheses; ranking and selection; distributions theory; and industrial applications.

The following conversation took place at the Department of Statistics, Purdue University, on 22 September 1997.

\section{THE EARLY YEARS}

McDonald: Shanti, it is a pleasure for me to be here talking to you. Having you as my major professor at Purdue many years ago was a great benefit to me both personally and professionally. Let's begin our discussion with your early years-growing up in India and your schooling in India. How do you see that now from your perspective?

Gupta: First of all, I want to thank you very much for honoring me in this way. The early education in India was primarily in the old city of Delhi. I did my high school there and then went on to St. Stephens College, where I did a B.A. Honours program in mathematics. The honors program means specialization. St. Stephens College was a part of the University of Delhi. Then I did an M.A. degree in mathematics at the University of Delhi. I learned primarily classical mathematics. I studied subjects like differential geometry, took courses on real and complex variables and other types of mathematics. I also studied hydrodynamics, statistics, materials, electricity and magnetism. I remember this last course very well, because it was a difficult course that required a lot of work. That was the education that I received in Delhi before coming to America. Since I was not sure when or if I would get a chance to study in the United States, I was also thinking of doing a Ph.D. in India. Incidentally, I did have a job as a lecturer in Mathematics right after receiving my M.A. in 1949.

McDonald: This was at Delhi College?

Gupta: At Delhi College. It was one of the older colleges affiliated with the University of Delhi much like St. Stephens. So during the period of 1949 to 1953, I contemplated doing a Ph.D. at the University of Delhi under the direction of Professor P. L. Bhatnagar, whose specialty was astrophysics. He and I discussed some books that he suggested I read. A year and a half or two years later, Dr. Bhatnagar got an invitation to go to Harvard University's astronomical center for a year or two. My studies in the area of astrophysics did not proceed very far after that. I then became interested in learning probability and statistics. I took some courses at the Indian Council of Agricultural Research on my own while still employed at Delhi
College. That is when I came into contact with Dr. Raghu Raj Bahadur, who was at that time employed at the Indian Council of Agricultural Research. Of course, there were other lectures I attended. This got me into studying probability and statistics at that time.

McDonald: This was while you were still teaching at Delhi College?

Gupta: Right.

\section{GRADUATE SCHOOL IN NORTH CAROLINA}

McDonald: How did you end up coming to the United States?

Gupta: That is a very good question. I could not have come to the United States on my own because my father had no money and I did not have financial support sufficient to travel and study in America. I applied for a Fulbright scholarship in 1952. Early in 1953, the results were announced and I received a Fulbright travel grant plus a SmithMundt Scholarship for one year of graduate study in the United States.

McDonald: Were you going to specialize in statistics at that point?

Gupta: I had by that time decided I wanted to pursue advanced studies in that area.

McDonald: How did you decide on the University of North Carolina?

Gupta: In that period of 1949-1952, I had met Dr. Bahadur and asked him which universities had good departments in statistics. He recommended a number of universities, including the University of North Carolina. I made a ranking of the universities I would like to attend, but the decision was more or less made by the Institute of International Education in New York. The Fulbright scholarship committee which works for the Fulbright Foundation had already arranged for me to be placed at the University of North Carolina.

McDonald: Thinking back on those days, who were some of your notable teachers?

Gupta: When I arrived in North Carolina in 1953, there were some very distinguished, wellknown statisticians there. The leading statistician was Professor Harold Hotelling, whose lectures and 
courses I attended. Professor R. C. Bose, who later became my thesis advisor, was another distinguished leading statistician at Chapel Hill. Other names that come to mind are Professor Wassily Hoeffding, Professor S. N. Roy and Professor Walter Smith, who arrived around 1954. Dr. Nicholson was the chairman of the department at that time.

McDonald: Your research work began with ranking and selection procedures and your career has really flourished in that area. How did you choose that particular area in which to do your thesis? What did you find attractive and challenging about it?

Gupta: At that time, I wanted to do research in some topic under Professor Bose. There were challenges and hopefully some possibility of making a good contribution on my own. I approached Professor R. C. Bose and asked if he would accept me as his student, which he did. He had some interest in the problems of simultaneous inference and also, to some extent, in the problems of multiple decision procedures. He had a student who had finished a year or two before me, Dr. K. C. Seal, who had written a thesis in this general area. When he suggested that I could work in that area, I was happy and started to follow up the research and to do some reading. It was a combination of the suggestions from Dr. Bose and my own research at that time that led to my decision to work in this area.

McDonald: Today we are accustomed to hearing the phrase "ranking and selection procedures." Was that phase part of the statistical jargon at the time you did your thesis work?

Gupta: Certainly not as it is today. The phrases "multiple comparisons" and "multiple decisions" were beginning to be used-multiple comparisons, of course, more so. But the phrase "ranking and selection procedures," as such, was not as common as it is now.

McDonald: The work that you did, Shanti, was in a particular area of ranking and selection procedures which we have now come to call "subset selection procedures." How did you come to focus on choosing a subset of the populations in order to make a probability statement as opposed to a fixed number of populations?

Gupta: Professor Bose had mentioned the general problem of multiple decisions to me, and I read some of the material in that area. Just about that time, Professor Bechhofer's paper had been published in the area of mathematical statistics. He was choosing the best or a fixed number of so-called best populations using the so-called indifference zone approach. I believe Dr. Bose and I found that in some situations the experimenter may not want to choose one best, or a fixed number, but would rather select a subset of worthwhile populations with a guaranteed probability of a correct selection, and then proceed from there.

McDonald: You mentioned Professor Bechhofer. When did you have the first opportunity to meet him and exchange ideas on ranking and selection?

Gupta: The date is difficult to pinpoint, Gary, but I believe I met him sometime in 1958 when I was already employed at Bell Telephone Labs. I had heard about him, and we had some correspondence before that.

McDonald: In your stay at North Carolina as a student, did you have any student colleagues that you were particularly close to or that had worked in areas that you found interesting?

Gupta: Yes, there was a large group of students doing their Ph.D. Many of these I met and have known since then. Professor S. K. Mitra, who later left and went back to the Indian Statistical Institute, finished a year or so before me. Don Burkholder did his Ph.D. with Professor Wassily Hoeffding and finished also a year before me. We took several courses together. Professor John Wilkinson, who went back to Canada and later came back to America, and Seymour Geisser, who was a Ph.D. student, were both there at that time. Ram Gnanadesikan was also a Ph.D. student. He finished, I believe, a year or two after I did. Those are the names that come to mind.

\section{EARLY CAREER}

McDonald: You certainly had a list of distinguished colleagues. After you left the University of North Carolina, I believe you went to work at Bell Labs. Can you tell us a little bit about your experiences at Bell Labs?

Gupta: Yes, that was a great experience. I started with Bell Telephone Laboratories in their reliability group in Allentown, Pennsylvania. There were a number of statisticians in that group. The main person with whom I interacted was Milton Sobel. I spent from July 1956 to June 1957 working in this group. The Bell Laboratories branch there was located in the Western Electric building. This was all part of $\mathrm{AT} \& \mathrm{~T}$ at that time. It was a very fruitful, enjoyable, successful year for me. I was able to write several papers and also do statistical consulting and applied work while I was working for them.

McDonald: What types of problems did you get involved with at Bell Labs?

Gupta: There were a few problems dealing with testing for life length and choosing the good components, the so-called best components, based on that. As you know, Gary, Bell Telephone Labs had come 


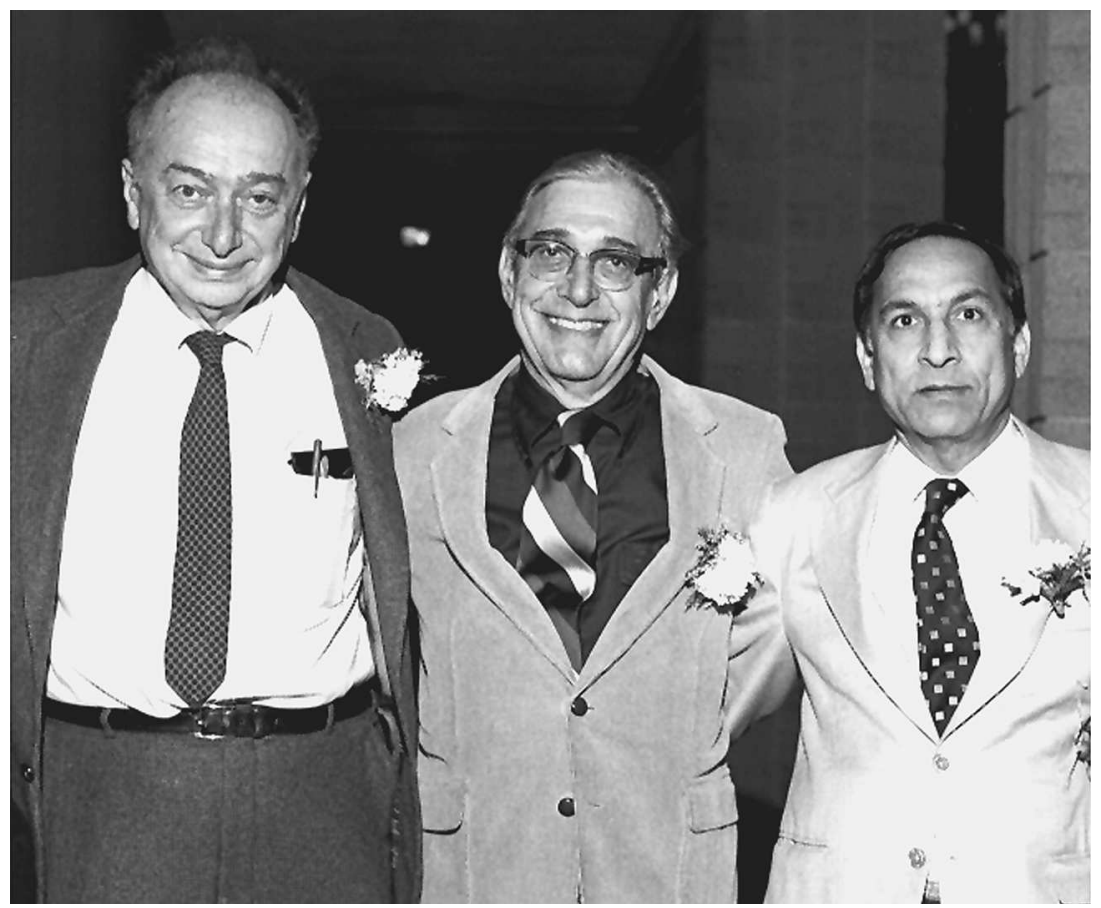

Fig. 1. 1984 "Statistical Ranking \& Selection: Three Decades of Development" Conference, Santa Barbara, California: (left to right) Milton Sobel, Bob Bechhofer and Shanti Gupta.

up with new devices at that time. The transistor was one of them. There was a great deal of work to be done by the engineers to improve the reliability. And the reliability estimation based on life testing was an important aspect of the research and development of the company. I participated in that general area.

McDonald: I know that both you and Milton Sobel have contributed tremendously to the area of life testing and reliability. Order statistics was actually a significant part of that work, an integral part of that work - calculating moments of order statistics and calculating the probability distributions of certain functions of order statistics. How long did you stay at Bell Labs?

Gupta: I stayed at Bell Labs for one year and returned there again in 1958 after a leave of one year in Canada, where I was teaching at the University of Alberta. I took a leave from them again in 1961-1962 to be a visiting faculty member at Stanford University.

McDonald: While in Canada, were you primarily teaching?

Gupta: Yes, that was a teaching appointment that consisted of two appointments. The first one was the summer employment at Northern Electric Company in Montreal, where I worked for approximately two months before going to teach at the University of Alberta. From September 1957 to May or June 1958, I was a faculty member of the Uni- versity of Alberta in Edmonton in the Department of Mathematics. I was teaching statistics there.

McDonald: Even while you were at Bell Labs in 1959-1960, you also taught at the Courant Institute?

Gupta: I always liked teaching. I mentioned earlier that, after my masters degree in India, I was a lecturer in mathematics. So, when the opportunity arose and the Courant Institute invited me to teach the evening classes as an adjunct faculty member, I got permission from Bell Labs to accept. In fact, they were very encouraging. I taught at the Courant Institute of Mathematical Sciences for two and a half years. I generally taught in the evening. The students were graduate students, mostly employees of various industries. I did this in 1959, 1960 and part of 1961, before I left for Stanford University.

McDonald: When you left for Stanford were you planning not to return to Bell Labs?

Gupta: No. At that time, I took a leave of absence without salary to go to Stanford. It was strictly a one-year visiting appointment. Herbert Solomon was the chairman of the Statistics Department at that time at Stanford. He offered me a position as visiting associate professor. I decided to switch into teaching and research, resigned from Bell Telephone Labs in 1962 and came to Purdue.

McDonald: Did you have a chance to interact with John Tukey while at Bell Labs? 
Gupta: I certainly had a chance to see him and talk to him about research in statistics. He was very nice to read some of the papers I wrote with Milton Sobel and to make some very good comments in general. I saw him many times in Murray Hill and gained lots of insight and ideas as to which way I should be moving and what problems seemed worthwhile. I had a very fruitful interaction in that sense. He was a very busy person during this time. $\mathrm{He}$ was teaching at Princeton University, as you know, and he was an Executive Director in Bell Telephone Labs communications research. Whenever arrangements could be made, I went to see him and frequently came back with many new ideas for research.

\section{MOVE TO PURDUE}

McDonald: What brought you to the Midwest and, specifically, to Lafayette, Indiana?

Gupta: As I said, Gary, from September 1961 to July 1962, I was at Stanford University teaching and doing research. I decided that I wanted to go full-time into university teaching and I started to apply for academic positions, one of them at Purdue University, which offered me a position. I came here to look over the university and the Department of Mathematics. At that time, Purdue had a division of statistics and there was a statistical laboratory. I met Dr. Felix Haas, who was the head of mathematical sciences at Purdue University. I was very impressed with him and realized that he was a scientist and mathematician with great insight into the future of the mathematical sciences. Certainly, he was very sympathetic to developing a program in probability and statistics. That was a very positive thing for me. I did have another offer from the University of Illinois in Urbana, but I decided to accept the offer made by Purdue University.

McDonald: When you came to Purdue, Shanti, statistics was not a department?

Gupta: That is correct. It was not a department. There was a group of people who could be called the nucleus of a statistics department and we were located in a building separate from mathematics. We were all part of that department. Some of us were called professors of statistics, others were called professors of statistics and mathematics.

McDonald: Who were some of the people in the statistics group at the time you came?

Gupta: The two names that come to mind are Irving Burr and Virgil Anderson. Dr. Anderson was the director of the stat lab as it existed at that time. Irving Burr was the most senior mathematics and statistics faculty member at Purdue. I had heard of him before coming here. There were a few other people who were doing probability research; e.g., Louis Cote, Harlley McKean and Henry Teicher.
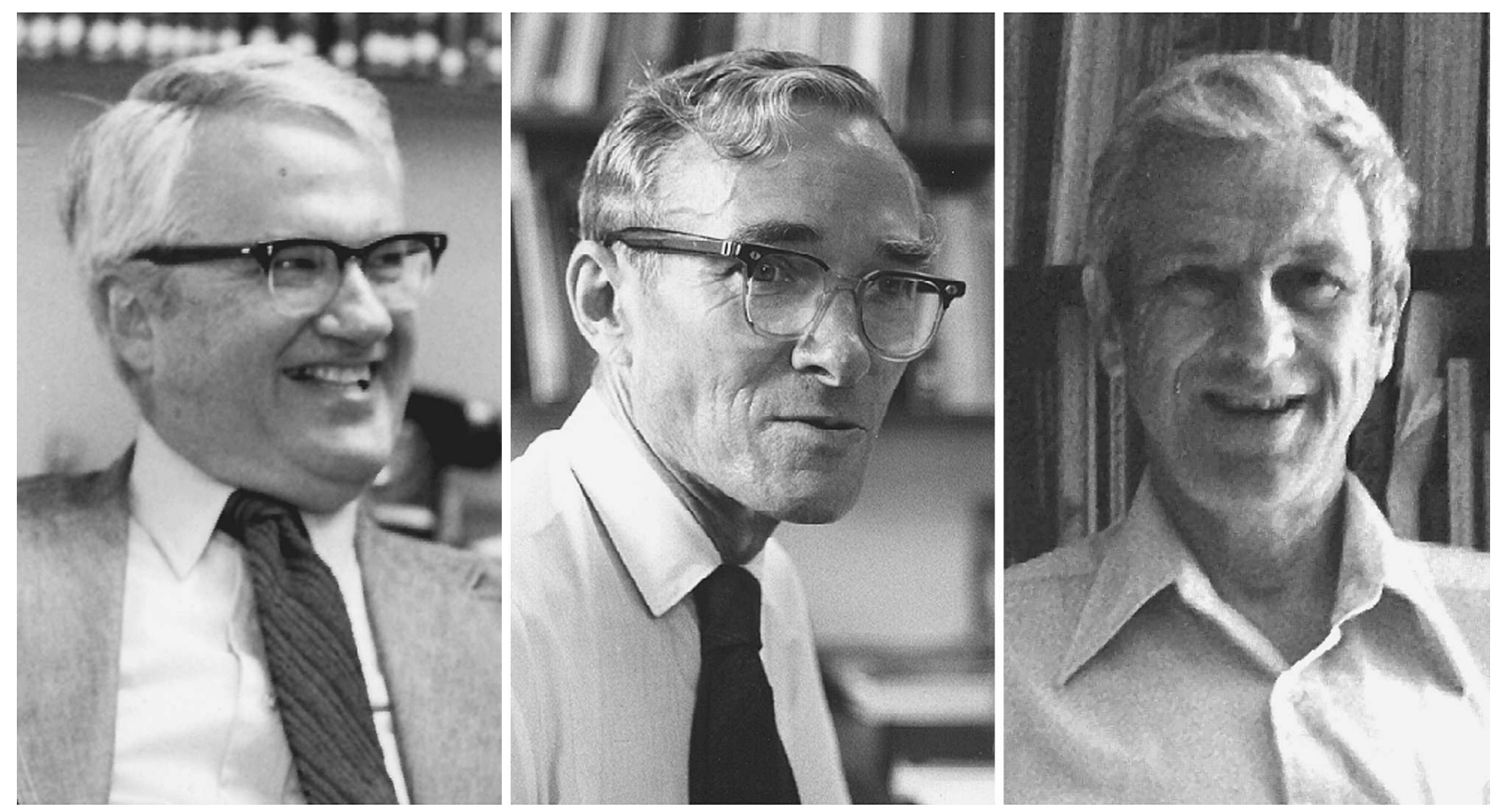

Fig. 2. Early members of the Statistics Department-(left to right) Virgil Anderson, Irving Burr and Louis Cote. 


\section{FORMING A NEW DEPARTMENT}

McDonald: How did the department progress from a division of the math department into a department in its own right? What were some of the challenges and some of the hurdles that you had to go through in order to make that transition?

Gupta: The department was officially created in 1968. During the period of 1962 to 1968, we had been able to gather together a nucleus of good people who joined the department of mathematical sciences as professor of both mathematics and statistics. These included Y. S. Chow and S. M. Samuels, working in probability; W. J. Studden, working in statistics; P. S. Puri, working in applied probability; and Herman Rubin, Glen Baxter, J. W. Yackel and David Moore, covering many areas of statistical education and research. Marcel Neuts, K. C. S. Pillai and I had come the same year, 1962. From 1963 on, I was instrumental in suggesting names, contacting people and indirectly helping to recruit them. We had gathered sufficient strength in terms of faculty research and interest in teaching statistics and probability. Therefore, in 1968, the administration, the Head of the Mathematical Sciences, and the Dean of the School of Science, who was at that time Dr. Haas, agreed to create a separate department.

McDonald: You became the first chairperson.

Gupta: I became the first chairperson. Nominally, I was in charge from 1966 to 1968, the actual department being created in 1968. I became officially the head of the department at that time.

McDonald: That is a position in which you served until 1996?

Gupta: 1995. A long time!

McDonald: During that time, you built the department into one of the country's great statistics departments. Did you have any particular goals that you set for yourself or for the department that you worked towards in the early days of the department?

Gupta: Thank you for saying what you said about the department. Yes, research was quite important to me. Of course, teaching was important also. Teaching was never considered secondary. At that time, research activity was being encouraged and a good deal of research funding was available through the NSF, the Army Research, the Air Force, the Navy Research and so on. I encouraged colleagues to be active in research and also, of course, do the basic job of teaching not only graduate students in our own program, but also teaching the so-called service courses. We accomplished this mission quite well. We were also, through Dr. Anderson's help, running a stat lab. Later its organi-

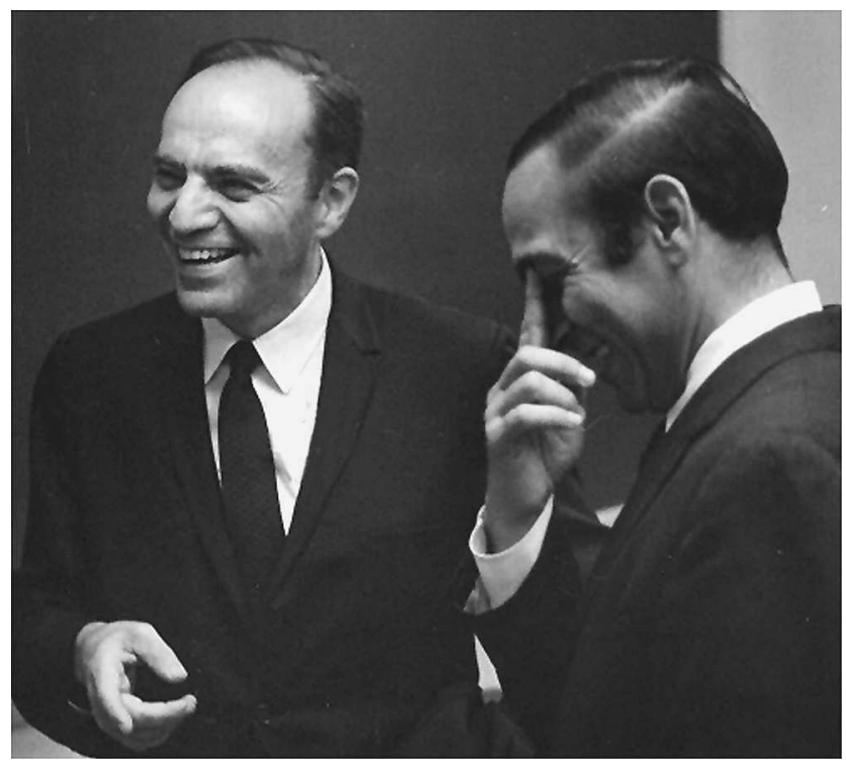

Fig. 3. Myer Jerrison, Head of Division of Mathematical Sciences, and Shanti Gupta, Head of Statistics Department, Purdue University, 1970.

zational structure was changed to become part of the Purdue University Computing Center. Statistical consulting, teaching in statistics and probability and research were the main thrusts. We were doing those things quite well. That has given me a great sense of achievement and satisfaction. I was able to get research funding from various agencies, the Office of Naval Research, the Air Force and the National Science Foundation, to support my personal research programs.

McDonald: Just looking at your publications over that period in time, namely, the time when you first came to Purdue for about 10 years, it seems to me pretty clear that your interest generated while you were at Bell Labs really did affect the direction of your research. It is very strong in selection rules, very strong in reliability, order statistics and life testing. Do you look at it that way? Do you think that the influence to which you were exposed at Bell Labs really set the tone of your research?

Gupta: Yes. Definitely so. Bell Labs was a great experience for me, as I said earlier. I saw the importance and relevance of statistical research coming through real life, real world problems. That certainly created a direction in my own mind of continuing research in those areas: reliability, life testing, order statistics. These are all important. After all, these are essential elements when you want to discuss, for example, inferences on the mean life. Is the mean life of a satellite or a transistor or a diode at least as big as some specified number? Then in that case, you do want to talk 


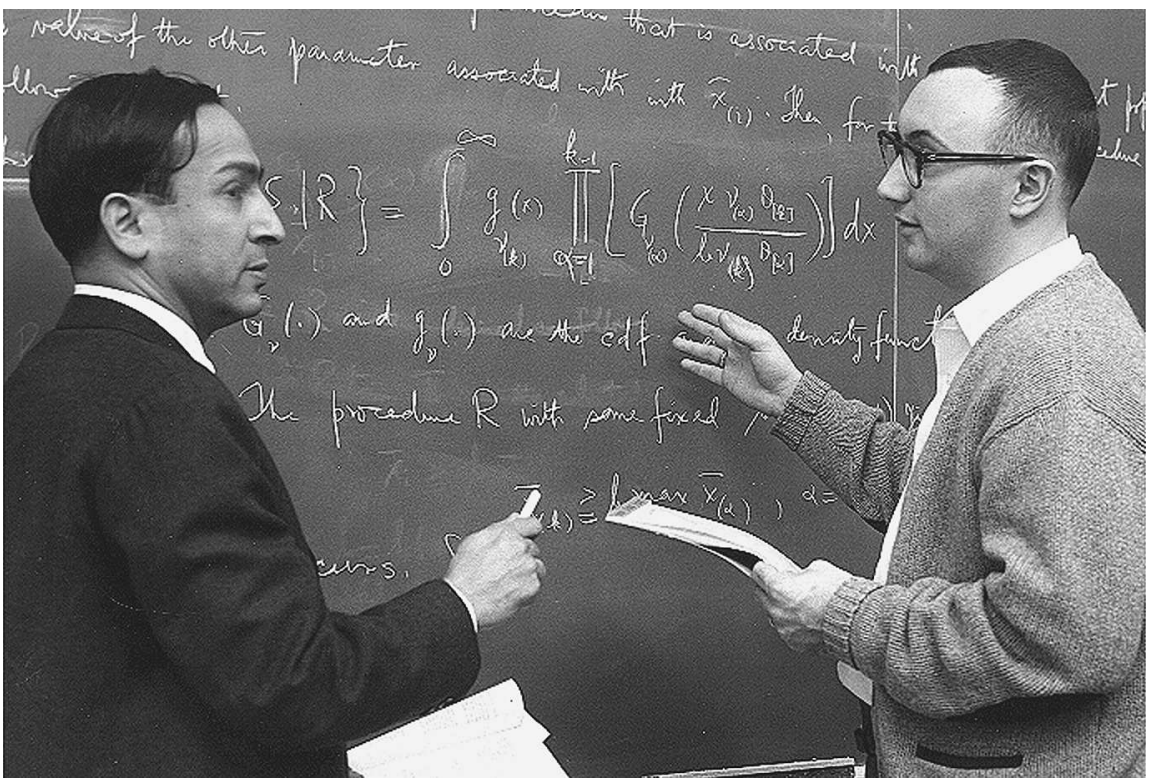

FIG. 4. Shanti Gupta and Jerone Deverman (Ph.D. 1969) working on a ranking and selection formulation.

about the moments, the expected value, the variance and so on. Moments of order statistics, estimation based on order statistics, inference based on order statistics, selection and ranking, all involve various facets of order statistics. In selection and ranking you choose the best, generally, in terms of selecting the largest or the smallest. So what you said is true, it did play a definite direction in my career and in the early development of the department at Purdue.

McDonald: As I look around the campus, in fact, as we walked over to your office today, I can't help but notice the campus has certainly changed over the last several decades. It is a much prettier campus, much softer with trees and foliage around the campus. When you look at the Statistics Department and you look at how that department has grown, changed and evolved over the last few decades, what comes to your mind? What are the major changes that you sense here at the Purdue stat department from the way it was when you first formed the department those many years ago?

Gupta: First of all, I agree with your observation about the university campus looking much prettier. There has been a great deal of improvement here since 1962. We moved the Department of Statistics from the old Engineering Administration Building to the new Mathematical Sciences Building in 1967. It certainly is much better here. The library for mathematics, statistics and computer science is located in this building. It is a great plus for the faculty and students to have the mathematical sciences library right here on the third floor of this building. The Purdue University Computer
Center is also very close. That is also a bonus for the statistics faculty doing research. In general, conditions have improved and the present head of the department, Dr. Mary Ellen Bock, has done an excellent job of providing all kinds of facilities, including the latest computing facilities for research and, of course, for providing additional and better equipment for teaching and lecturing.

McDonald: Have you noticed any changes in the student body over the same period of time? Are you getting more students applying to the stat program or different types of students applying from what you had back in the 1960s?

Gupta: We certainly are getting more applications. The mix of the applicants has changed quite a bit. There are no restrictions. We can admit students from practically anywhere in the world if they are qualified. We receive a large number of applications from all parts of the world. Unfortunately, we do not receive as many applications from good American students as we would like to have. We do receive applications and admit students from the United States, but the number has been rather small. However, things seem to be improving. We have been advertising the programs through the usual channels, e.g., Peterson's Guide and the Internet, and also by sending letters.

McDonald: Purdue has become fairly well known for their symposium series. I believe that you were instrumental in getting that program started. How did it get started and how many symposia have you had?

Gupta: When I came to Purdue and as we started gathering strength in statistics and probability, I 


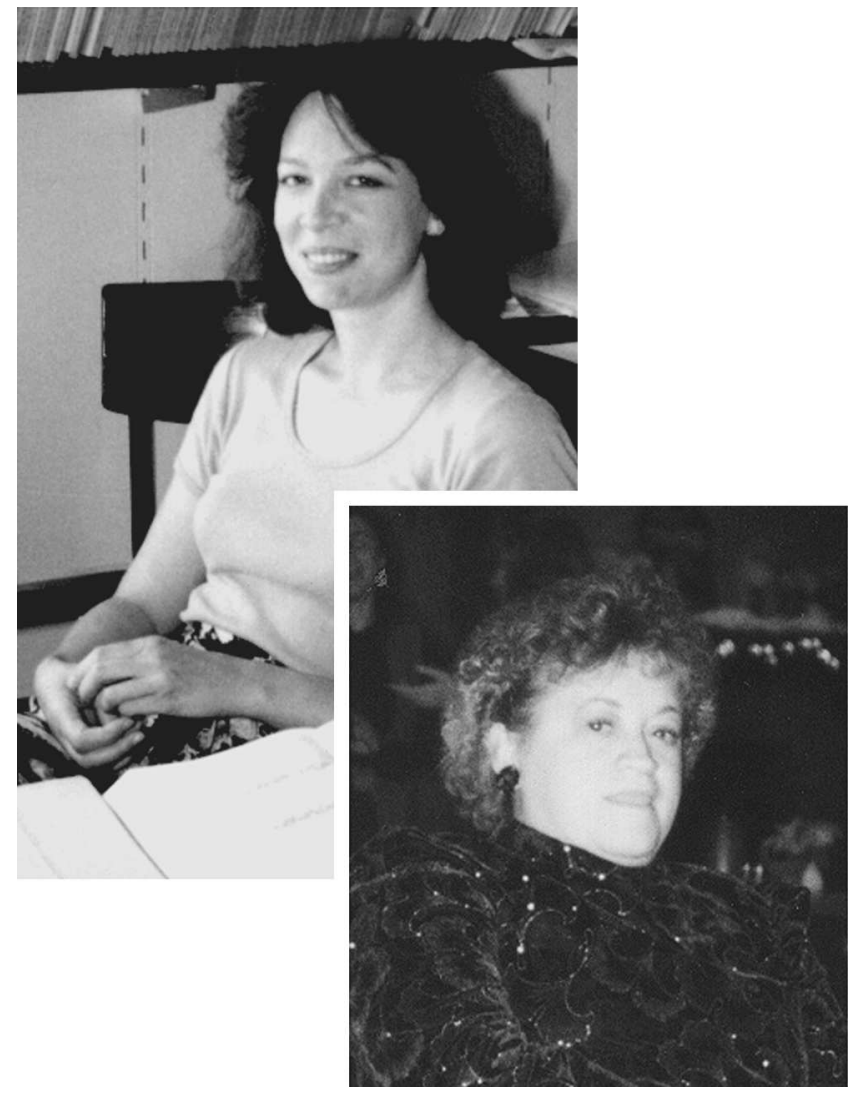

Fig. 5. New Statistics Department Head, Mary Ellen Bock (left), and Department Administrative Assistant, Norma Lucas (right).

saw a need for holding a regular series of symposia for exchanging research ideas and providing a forum for research discussions. In 1969, we started planning for the first symposium, which was held in November of 1970. It was entitled, Purdue Symposium in Statistical Decision Theory and Related Topics. The second symposium followed with the same title in 1976. We have had five of these, the most recent one being held in 1992. In each case we had the papers refereed and proceedings published. That has been a great source of satisfaction and pride for me. The quality of the symposia has been very good, and the international and national participants that have come have made some very nice comments about them.

McDonald: And do you have plans to continue with the symposium series?

Gupta: We are planning to have the sixth symposium in June 1998. It will be a little broader in some respects. There will be two workshops: statistical genetics, organized by Rebecca Doerge, and statistics in nutrition, organized by George McCabe. The main conference on statistical decision theory and related topics is being organized by Mary Ellen Bock and myself. Jim Berger is organiz- ing a workshop on the interface between statistical paradigms.

McDonald: Do you see the symposium continuing even beyond next year? Do you anticipate that this will become a cornerstone of the Purdue Statistics Department?

Gupta: I very much hope so. The nature and the emphasis might change and should change with the times, but I think they will.

McDonald: Shanti, as you look at the Statistics Department at Purdue, what strikes you as the particular strengths of the department? What areas do you think this department really is well noted for?

Gupta: Largely speaking, the areas of research that are present in the department revolve around Bayesian analysis, decision theory, general decision theory as well as multiple decision theory, which is selection and ranking, multivariate statistical analysis, design of experiments, particularly optimum design of experiments theory, categorical data analysis, reliability and stochastic processes. We have a good group of people, some holding joint appointments with mathematics, who are very active in research in these areas.

\section{PROFESSIONAL ACTIVITIES}

McDonald: Shanti, let's turn to some of your activities that are maybe more professionally oriented and not so much Purdue oriented, although there is certainly overlap. In particular, how have you been involved with the IMS, Institute of Mathematical Statistics?

Gupta: I have been fairly active in the activities of the Institute of Mathematical Statistics for a long time as Chair of various committees, starting with the committee dealing with the visiting lectures program. Back in 1968-1969 and for another two years or so after that, I was the director of the visiting lectures program for the IMS. In this program, faculty members are encouraged to make presentations at smaller colleges and universities where they are invited to talk about the professional opportunities for students and about careers in statistics. After that, I started the so-called Lecture Notes-Monograph Series in statistics. I was the first editor for getting the series started and I continued as its editor for about six or seven years. In this series, on behalf of the IMS, we invite people to write lecture notes-monograms on the subject of their expertise. Then they are refereed and go through the usual publication process with the IMS at a very minimal cost to the members and to the general public. If you were to publish the same book through a commercial publisher, it would 


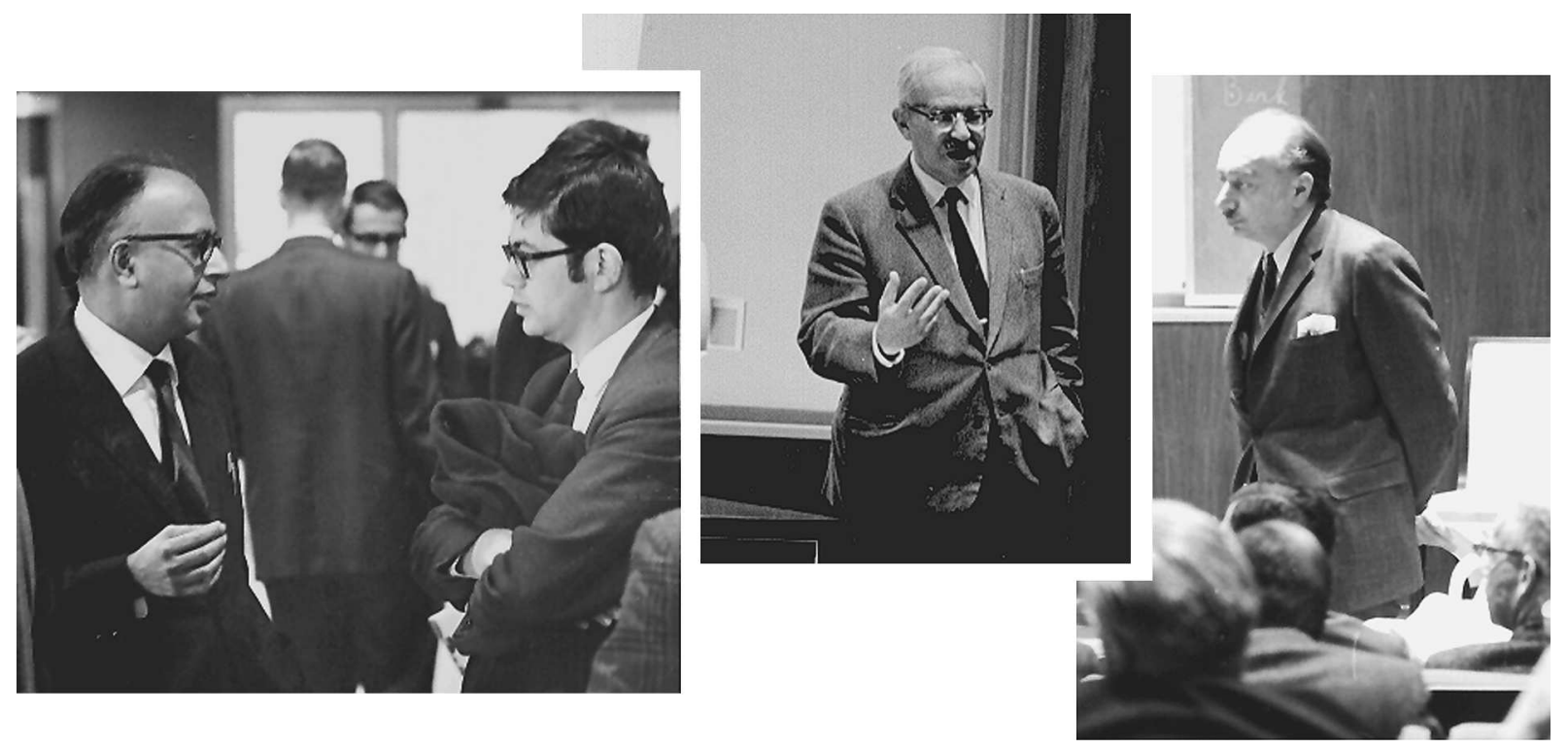

Fig. 6. First Purdue Symposium on Statistical Decision Theory and Related Topics held at Purdue University, November 23-25, 1970: (left) Raghu Raj Bahadur and Peter Bickel; (center) Jerzy Neyman; (right) Milton Sobel.

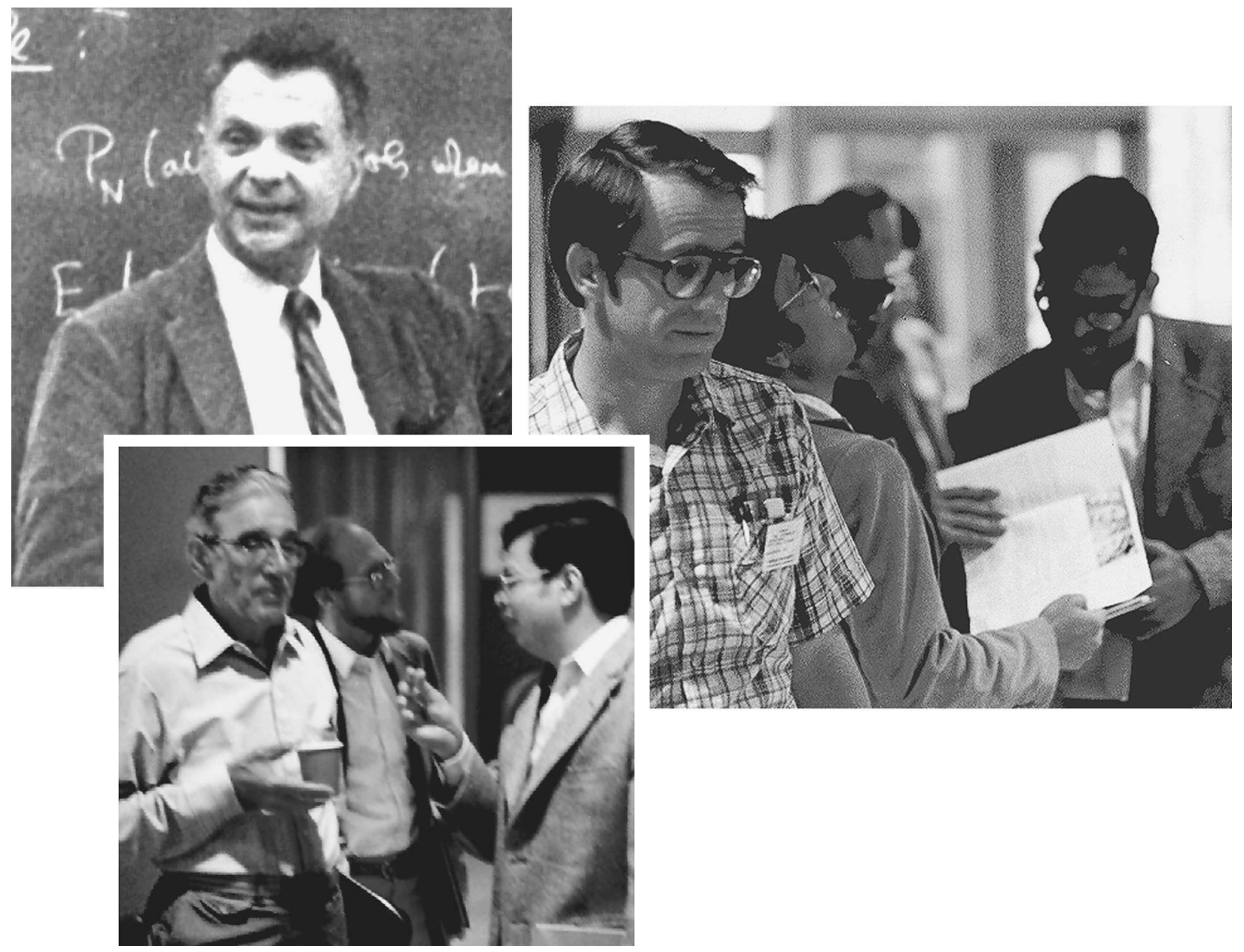

Fig. 7. Attendees at the 1981 Purdue Symposium: (top left) Herbert Robbins; (top right) Gary McDonald (Ph.D. 1969), Prem Goel (looking up) and Prem Puri; (bottom left) Bob Bechhofer, Ray Carroll (Ph.D., 1974) and Ajit Tamhane. 
be much more expensive. We are thus able to get new research topics brought to the attention of the IMS members and the statistical community quicker and cheaper than would have been possible otherwise.

McDonald: You then served as President of the IMS?

Gupta: Yes, I was elected a member of the IMS Council back in 1977 for three years. Later, in 1987 or 1988 , I was asked by the nominating committee of the IMS whether I would be agreeable to be nominated for the position of President-Elect. I became President-Elect in 1988 and President in 1989-90. This was a great honor for me.

McDonald: During your tenure as President, was there any issue or topic that surfaced as particularly important at that time?

Gupta: Yes, there were some issues. One issue that was somewhat ongoing, but took a little more momentum when I was President, was that of young researchers. The IMS, like other organizations, was interested in the improvement of young people who were recent $\mathrm{Ph}$.D's coming into the profession. Steps were taken to encourage them to have their own conferences called Young Researchers Conferences. It was done through a succession of steps and a committee was appointed. The direction of the Young Researchers Conference and associated activities took a more definite shape during my tenure as President. Besides this, there was a question of additional publications of the IMS, other than the IMS Lecture Notes-Monograph Series and journals. Some of these had already been started, but the question of the joint publication by the IMS and ASA was brought up. The IMS had been active in jointly sponsoring the publication of the Current Index to Statistics in which I had also been involved at one time on behalf of the ASA and the IMS as the managing editor of that particular se- ries. The momentum then was primarily in the area of publications and the area of encouragement to the young researchers. Also, some joint efforts took place. The first joint meeting of the IMS with the Bernoulli Society, which is also an international society, took place in 1990. I was involved with the planning for that event.

McDonald: Sounds like a busy time.

Gupta: Yes, it was.

McDonald: You have also been involved with other journals and other statistical media for communication, e.g., Journal of Statistical Planning and Inference, Communication and Statistics and Sequential Analysis. Are you still spending a lot of time with them?

Gupta: Not as much as I was doing a few years ago. I am still involved with the Journal of Statistical Planning and Inference, Sequential Analysis and also a journal called Statistics and Decisions. I have been involved with the Journal of Statistical Planning and Inference for many years. I was its Editor-in-Chief, from January 1989 to December 1991 and am still on its Advisory Board. I am on the editorial board of two other journals as well.

McDonald: Let me just go back briefly to the issue of the funding for statistical research. I know that you had substantial support for research in your particular areas through several government organizations. How do you see the federal support for statistical research today versus what it was 5 or 10 years ago?

Gupta: As I see it, the federal funding has certainly not increased and the emphasis for research support has certainly changed. It has moved more in the direction of research which is more relevant to problems that arise in practice. I think this is fine. The agencies, Office of Naval Research, Army Research Office, the Air Force, continue to provide some funding for basic research. But it's definitely

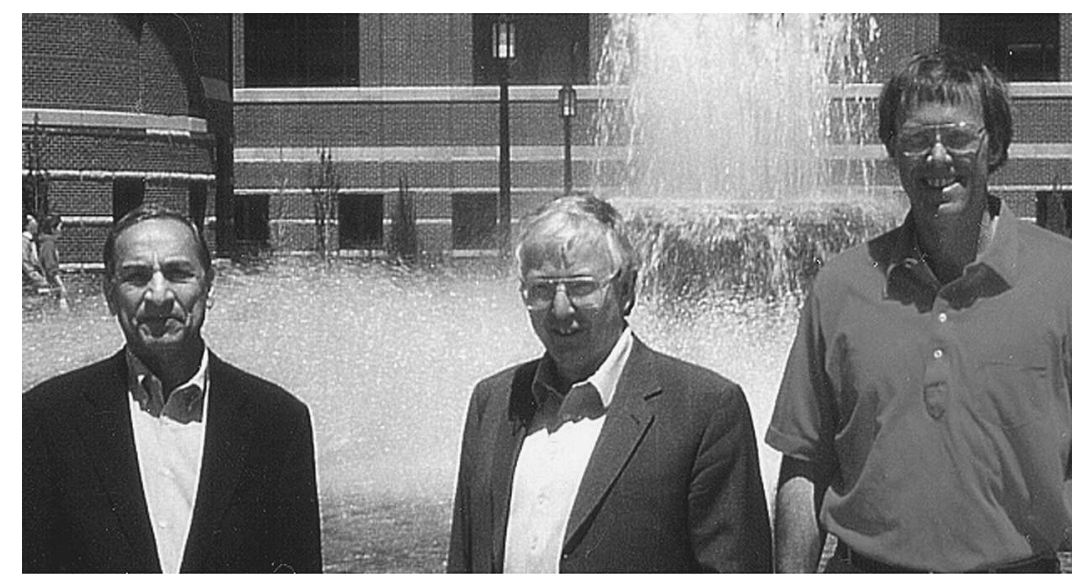

FiG. 8. Shanti Gupta, Klaus Nagel (Ph.D., 1970) and (right) Jim Berger. 
less than, say, a decade or two ago. I think this is also true of the National Science Foundation. In comparison to the early $1960 \mathrm{~s}$, things have certainly changed. As I see it, overall funding for basic research has not kept up or has decreased.

McDonald: Do you think that comes from the field of statistics maturing or do you think that it is possibly because we haven't done an adequate job of indicating where the benefits of good statistical research can be focused?

Gupta: The field of statistics has certainly matured as you pointed out. I think the statistical community has not done an adequate job of letting others know how we can better serve them via what we have done.

McDonald: Let me turn back again to your experiences at Purdue, Shanti. I think you have had $28 \mathrm{Ph} . \mathrm{D}$. students complete their theses under your direction. Maybe my number is one or two off, but somewhere in that order. I know all 28 students would be significant in their own right, but maybe there is some particular highlight or two that you would like to share with us on your experiences with your students.
Gupta: I have been very fortunate in having the opportunity to have these illustrious, great students work with me. They all did significant, interesting research work for which they earned their Ph.D. Most of them worked in the area of multiple decisions, selection and ranking, with emphasis also on the aspects relating to applications and reliability. Certainly our association started that way. I am very honored and pleased that you chose to come and work with me. That was a great thing that happened in my life and brought me in touch with challenging statistical problems based on your work at General Motors. Professor Panchapakesan, with whom I have done so much collaboration, including a book, definitely gave an impetus to continuation of my research. This has been a great stimulus for me. More recently, I have been working in the area of empirical Bayes for the problem of selection and ranking, but from the large sample viewpoint where past data provide some information about the prior distribution. Empirical Bayes decision-theoretic formulations for selection and ranking have been going on for the last 10 years with Dr. Ta Chen Liang, who is currently a faculty member at Wayne State

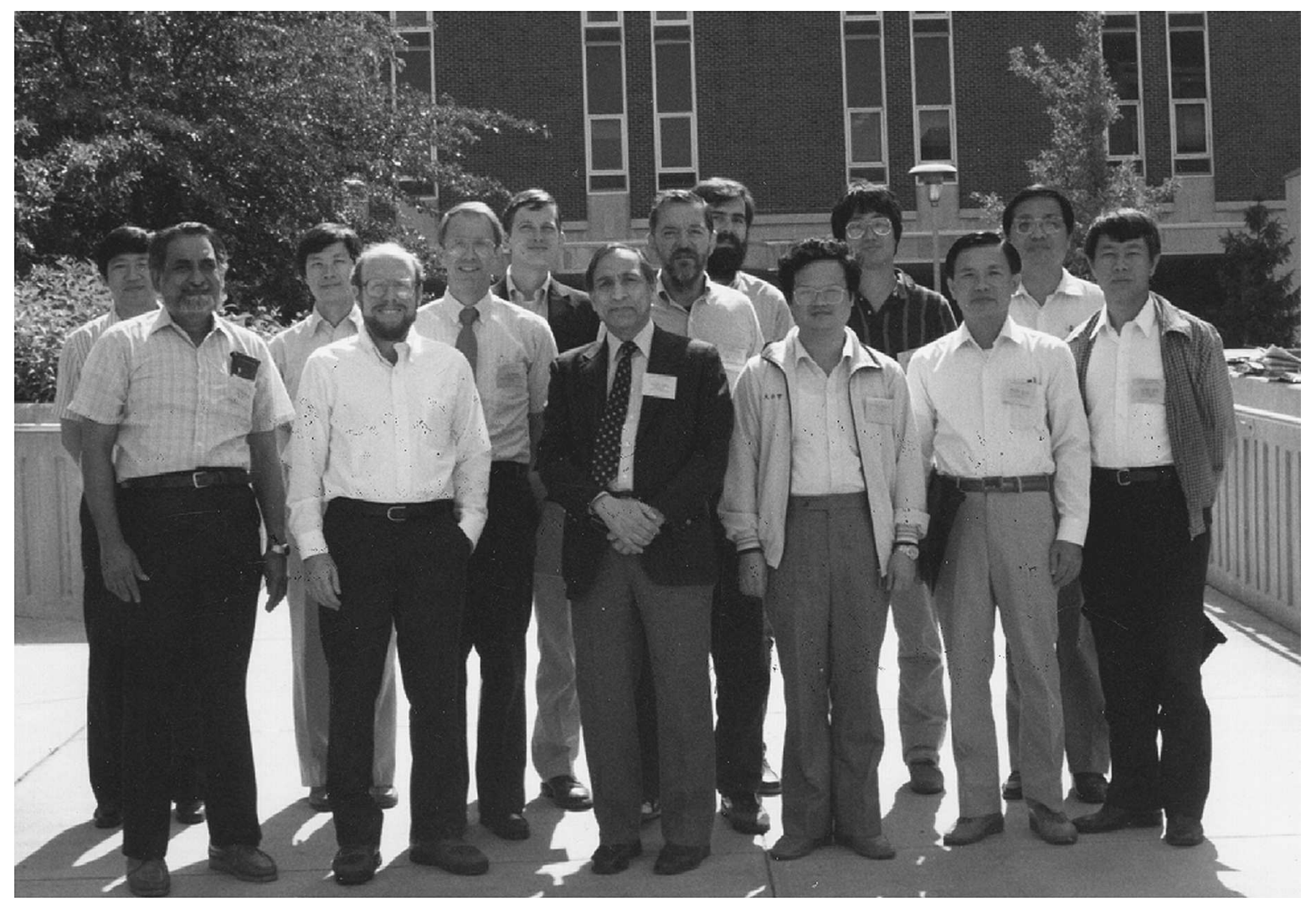

Fig. 9. Shanti Gupta with some of his Ph.D. students at the 1986 Purdue Symposium: (left to right) Woo-Chul Kim, S. Panchapakesan, Jason C. Hsu, Raymond J. Carroll, Gary C. McDonald, Thomas J. Santner, Shanti Gupta, John J. Deely, Roger L. Berger, Lii Yuh Leu, Joong K. Sohn, Wen-Tao Huang, Deng-Yuan Huang and Ta Chen Liang. 
University. I've worked with other past students, especially Dr. D. Y. Huang and Dr. W. T. Huang. So, overall, collaboration with students and former students has been a matter of great satisfaction for me. I've been fortunate to be involved with the young people who are leading statisticians all over the world in their own right. Three of my Ph.D. students (McDonald, Carroll and Deverman) have been recognized as Distinguished Alumni of Purdue's School of Science.

\section{PERSONAL SIDE}

McDonald: I know you really enjoy traveling. I think, with your students scattered throughout the world, it gives an opportunity to visit them and learn things that are going on in their particular areas of the world where they are either teaching or working. Do you still travel significantly?
Gupta: I still travel but not as much as I was doing 10 or 15 years ago. I certainly enjoy traveling to places, meeting people, giving lectures, meeting my former students who are well established and meeting their colleagues in their universities or at work sites. I have been to South Korea to see Dr. Woo-Chul Kim and Dr. Joong K. Sohn. I have visited Taiwan several times, especially the Institute of Statistical Science of the Academia Sinica, where Dr. Wen-Tao Huang is employed. I've also visited Dr. L.-Y. Leu, Dr. Deng-Yuan Huang and several other people in Taiwan. I have been to Germany on several occasions to meet with fellow researchers such as Dr. Klaus Miescke, and previous students such as Dr. Klaus Nagel.

McDonald: Well, we talked a lot about statistics; I am wondering if you have time or interest for any hobbies outside of statistics and travel. What do you do with your free time?
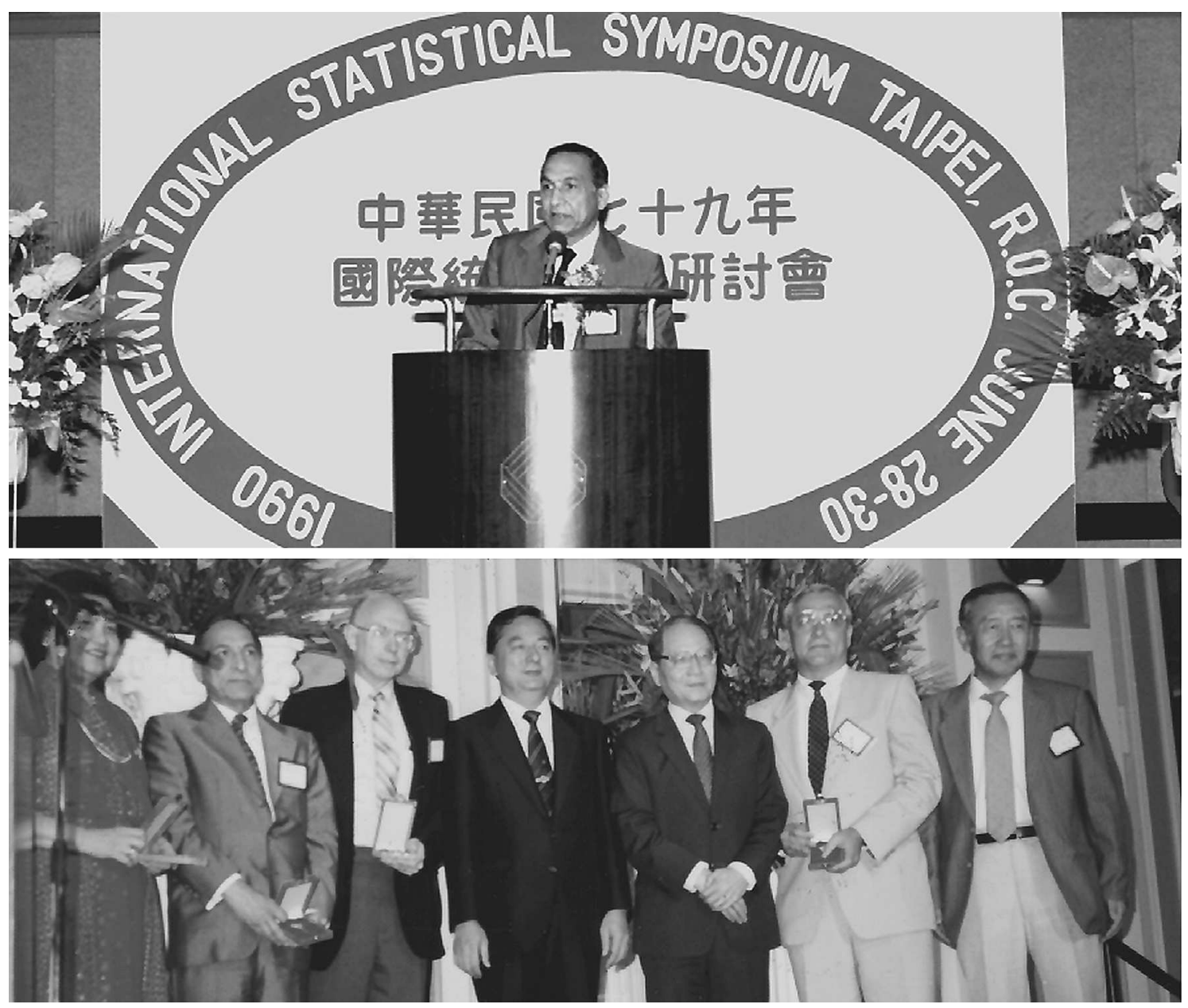

FIG. 10. 1990 International Statistical Symposium, Taipei, ROC. Honored guests (left to right): Miss Khoo Chian Kim, Chairperson of the Bureau of Statistics of Singapore; Professor Shanti Gupta, Purdue University; Professor Ronald Pyke, University of Washington; Ta-Chou Huang, Acting Mayor; Chien-Min Yu, Director General, DGBAS; Professor Stephen Fienberg, Carnegie Mellon University; and Tzong-Shian Yu, Academia Sinica. Miss Kim and Professors Gupta, Pyke and Fienberg receiving Keys to the City. 
Gupta: I do not have any real hobbies other than reading. To relax, I go to the health club or Purdue gym and do a little exercise and a little swimming. I like to travel and do sight-seeing. That is usually not a separate activity. Rather I combine the sight-seeing with conferences or business-related trips.

McDonald: We should note for the readers that not only do you contribute to Purdue, but your wife is also a faculty member at Purdue University. How did you meet her? What does she do at Purdue?

Gupta: I met my wife, Marianne Heinicke, in 1971 here at Purdue University. We were married in 1974 . She is currently a faculty member in the School of Liberal Arts. Her primary duties include the supervision and general guidance of undergraduate foreign language majors and students at Purdue who want to study abroad for a year or so as part of the Purdue exchange programs. She has been an excellent teacher and a very resourceful person who helps out these students a great deal. She is an extremely kind and nice person and it has been my great joy to be married to her. We have a daughter, Maya, who is 19 years old and a student at Columbia University. This year she is studying at University College London. Her majors are Psychology and French, a double major. We are both very happy that Maya is part of our lives.

\section{THOUGHTS ON THE FUTURE}

McDonald: Let's turn our thoughts to the future now. You've stepped down as Department Head, but you are certainly still very active in the teach-

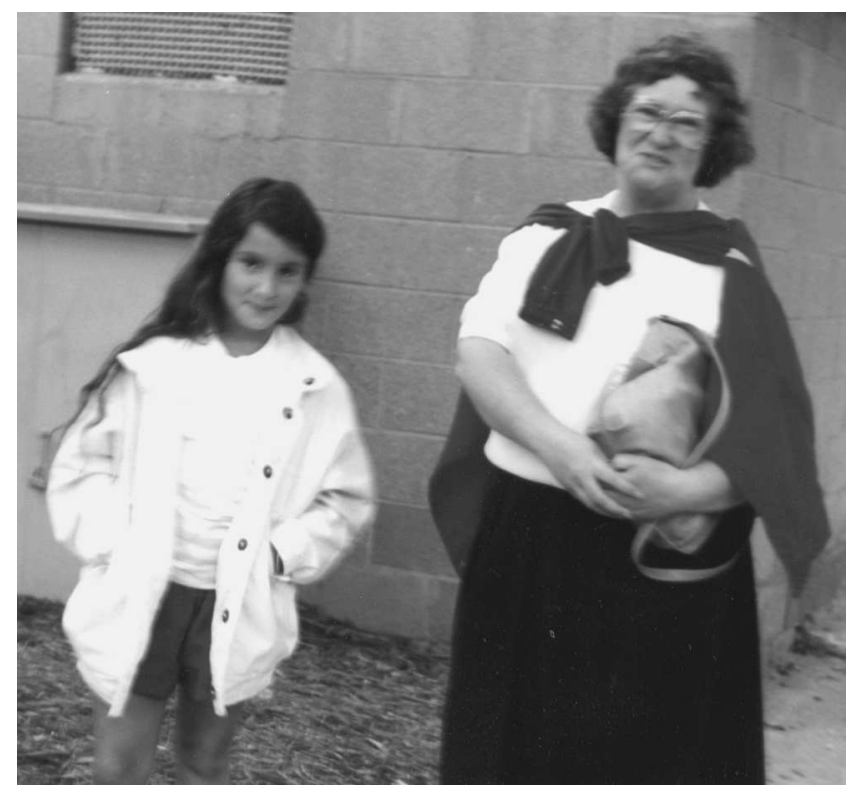

FIG. 11. Shanti's daughter, Maya, and wife, Marianne. ing and the research phase of statistics. What areas of research are you going to continue to pursue? Are there new areas on which you intend to focus?

Gupta: I am teaching and continuing my research. I will be thinking of some more problems which are application-driven. I do not mean that what I have been doing is not applicable. It is a matter of great satisfaction when I go to conferences and see the possibility of applications of selection and ranking, or the actual applications themselves. That work will continue. But I will focus more on real-life application problems which arise in analysis and design of experiments, selection and ranking and simultaneous inference. I'm also interested in the problems where you wish to not only select but also estimate the parameters associated with the best population based on the same data. This last area is quite useful and seems to have a lot of potential. Not too much research in this area has been done. There are about 10 to 20 papers published and a few joint papers that have been written by Dr. Miescke and myself.

McDonald: Do you have any thoughts about the directions of the profession and how it might evolve as we begin to think about the turn of the century?

Gupta: I think the statistical profession will have a great future. Just the area of medical statistics, largely speaking biostatistics, is booming with possible applications and new problems, most of which involve statistical analyses. Medical statistics, biostatistics, agricultural statistics, life sciences and the genome project, you name it-I think the applications are growing and you yourself have a big role, nationally and internationally, in the interfaces of statistics with other sciences. So I don't have to really mention all this to you. A great feature of statistical science is that it has not only theoretical aspects, but also applications. The interface with applications and with other sciences is so broad and expanding. Of course, the advent of and progress in the computing field has provided a great deal of impetus. Some of the problems that could not have been done 20 years ago are much easier to handle now in statistical computation. This is very clear in the field of business statistics where very important statistical computational tools such as Markov Chain Monte Carlo and other methods are being used. What would have been difficult to imagine to solve or make a special contribution to, say, 10, 15 years ago, is very possible now. These are all very positive developments and I think the statistical profession has a great future.

McDonald: Do you see any trends or any significant changes in the education of students that might be important to our statistical audience? 
Gupta: I think the basic approaches to the teaching and learning of statistics are improving. It's becoming easier in some ways because of the computers and Internet availability - the information is available. You can provide course listings, contents, resource material, examples, problems for use by anyone, anytime, anyplace. More and more people find it easier to supplement learning that way. Now, of course, there are the more advanced aspects of any topic and any discipline which have to be taught in a classical classroom environment. I think the educational system is changing for the better and the statistics programs will certainly be affected in a positive way.

McDonald: Those changes that you mentioned will probably have a two-pronged impact. One is that the students that come into your program will have a background that is certainly stronger in computing and information technology than what we had here before. That by itself will bring a new degree of excitement and challenge to the collegiate teaching, I would think. How about the future with respect to the professional associations-The Institute of Mathematical Statistics, the American Statistical Association, the Statistics Section of the American Association for the Advancement of Science? How do you see the challenges that they are going to be confronted with in order to serve their membership more effectively as we move into the new century?

Gupta: I think the IMS, ASA, the AAAS and other societies are moving in the right directions. They are aware of the big changes that are taking place in information technology. They are gearing themselves up for electronic publishing, distance learning, remote teleconferencing, educational seminars and workshops, etcetera. These items are beginning to appear in our annual meetings. I think the societies will do well. Whether it will come to a point that, at a given moment, they might say, "well, this year we will not have an annual meeting at a given place, we will do it all on the Internet," that is something else. For me, at this stage of my life, it is difficult to imagine. Using this information technology to an extent that we don't even have to get together, perhaps, is not ideal. Using it to the extent that every publication would be available on the screen is another matter. That is a question of timing. In general, the societies will continue to flourish and adapt themselves.

McDonald: Shanti, you have published more than 150 articles or papers. Do you have a select few of these publications that you feel are particularly seminal for the profession or that you feel are particularly stimulating in terms of leading to other papers and other work?
Gupta: I suppose there are. One that comes to mind is the basic paper on subset selection procedures that I published in a 1965 issue of Technometrics. That was a special issue in which several statisticians had papers on the topic of multiple comparisons. That paper certainly has had some basic impact on the research community for many years.

McDonald: This is the one that is "On some multiple decision (selection and ranking) rules?"

Gupta: That is correct. In the area of nonparametric or distribution-free procedures, for special selection and ranking problems, the several papers that you and I did were quite seminal. Certainly, the one basic paper published in the proceedings of the conference at Indiana University on Non-Parametric Statistical Inference, edited by M. L. Puri, made its impact. It opened the way of looking at problems where the parametric assumptions were not justified or not quite true. That area of work, jointly with you, opened up a question for more research here and continued to stimulate a number of papers that have been written. Two of these papers are with Panchapakesan on designing experiments with selection and ranking goals. Several papers on empirical Bayes approach stand out quite well. They were joint with Ta Chen Liang and Sayaji Hande.

McDonald: Have you kept up your association with Milton Sobel? We mentioned him earlier on with your work at Bell Labs.

Gupta: We certainly have been in touch with each other, although we have not done any joint research. Part of the reason being that we have been separated by this long distance. He, as you know, is at the University of California in Santa Barbara and here I am at Purdue-it's quite a distance. We know of each other's work and we meet at professional meetings. He has been at Purdue several times, including the Purdue Symposia. In that way, we are connected.

McDonald: Do you have any plans for books? Might I suggest that you update your book with Panchapakesan as a project?

Gupta: That will be a good thing to do. If Panchapakesan can do it, more power to him! I hope that can be done. We will leave it at that.

McDonald: Are there any other topics that we should be talking about, Shanti, or that you would like to note?

Gupta: I would just like to mention Purdue University and its administration, the Department of Statistics and its faculty. I have visited many universities, been on review panels for departments in other universities, but I would just like to observe 
that this university has not only been kind to me, but I feel that it has a great administration. The Department of Statistics is in very good hands. The department head, Dr. Mary Ellen Bock, is doing an excellent job in providing all the facilities and with appropriate emphasis and recognition for research and teaching. Teaching is very, very important, second to none, in her mind, in my mind and in the minds of the faculty. We also, of course, continue to provide a statistical consulting service to the University and the Purdue University Computing Center. This is headed by George McCabe, who was hired back in 1970 and has built up this service very nicely. This is a great service to the scientific and engineering communities.

McDonald: Your comments on teaching reminded me that in 1996, the Shanti S. Gupta Dis- tinguished Professorship was established to recognize excellence in teaching. Who currently has the Distinguished Professorship?

Gupta: That Distinguished Professorship is held by Professor David Moore. David, as you know, is one of the very best in the field of statistical education. He is a very successful author, coauthor and a great statistician.

McDonald: I think that is a great recognition for both you and Professor Moore. In conclusion, I would like to thank you, Shanti, for your contributions to the statistics profession and to Purdue University. We are all looking forward to your future contributions. Thank you very much for sharing your thoughts and remembrances with us.

Gupta: Thank you, Gary. I appreciate your congeniality, interest and effort. 